\title{
La maternidad a través de las prácticas discursivas de mujeres adultas
}

Martha Cecilia De Luna Cortes ${ }^{1}$ y María Gabriela Luna Lara ${ }^{2}$

\section{Resumen}

El objetivo de esta investigación fue identificar los elementos discursivos a través de los cuales un grupo de mujeres adultas construye el concepto de maternidad, considerando sus efectos normativos y cómo se mantienen. La selección de las participantes se basó en un criterio de conveniencia, todas mujeres en un rango de edad entre 23 y 37 años y el nivel educativo igual o superior a licenciatura; También se consideró si tenían hijos o no. Los datos se recopilaron a través de grupos focales. Todas las entrevistas fueron grabadas, transcritas y analizadas, utilizando el

1 Universidad Autónoma de Aguascalientes, cecy.deluco@gmail.com

2 Universidad de Guanajuato 
enfoque de análisis de repertorios interpretativos como base teórica y metodológica. Se identificaron tres modelos de maternidad: hegemónica, moderna y maternidad como opción. En cuanto a las prácticas discursivas, se identifican un total de 9, de las cuales 3 se utilizan cuando se habla del modelo hegemónico y las 6 restantes con otros modelos.

Palabras clave: maternidad; mujeres adultas; análisis del discurso; prácticas.

\section{Abstract}

The aim of this research was to identify the discursive elements through which a group of adult women build the concept of motherhood, considering their normative effects and how they are maintained. The selection of participants was based on a criterion of convenience, all women in an age range between 23 and 37 years and the educational level equal to or higher than college; It was also considered if they had children or not. Data was gathered though focus groups. All interviews were recorded, transcribed and analyzed, using the analysis of interpretive repertoires approach as a theoretical and methodological basis. Three models of motherhood were identified: hegemonic, modern and maternity as a choice. Regarding discursive practices, a total of 9 are identified, of which 3 are used when talking about the hegemonic model and the remaining 6 with other models. 
Keywords: maternity; adult women; discourse analysis; practices.

La práctica de la maternidad es tan variada como la cantidad de mujeres que se encuentran inmersas en ella. Diversas investigaciones respaldan la existencia de múltiples formas de ejercer la maternidad, las cuales han sido agrupadas de acuerdo a sus características y se les ha dado el nombre común de modelo, término que hace referencia al "arquetipo o punto de referencia para imitar o reproducirlo" (Real Academia Española, 2014). Así pues, al establecer una serie de lineamientos, los modelos indican cuáles son los requisitos necesarios que una mujer debe cumplir al convertirse en madre. Estos son construidos y compartidos de persona a persona a través de diferentes medios, siendo uno de ellos el discurso, el cual resulta esencial para comprender cómo la sociedad crea, promueve y mantiene estos arquetipos. La presente investigación tuvo como objetivo identificar cuales son los modelos de maternidad inherentes a las prácticas discursivas de un grupo de mujeres adultas, así como sus características principales y la forma en éstos que se mantienen.

La maternidad es un concepto dinámico pues, al contrario de lo que se cree comúnmente, su significado se ha ido modificando a través del tiempo (Barrantes y 
Cubero; 2014; Molina, 2006; Oiberman, 2004). En la época de los griegos, la maternidad era elevaba al nivel de las mismas deidades, adjudicándole las características que éstas poseían, tales como pasividad, generosidad, fecundidad y de soporte nutricio para la vida. Con el advenimiento de la tradición judeocristiana, la maternidad fue concebida desde un nivel más terrenal debido a Eva, mujer considerada hueca, débil y caprichosa. Dicha imagen era combatida comportándose de forma abnegada y obediente, tal como la virgen María. En la edad media, la maternidad se construyó a partir de aspectos puramente fisiológicos: procreación, gestación, parto y amamantamiento. La crianza de los hijos adquirió importancia sólo hasta la era romántica y se colocó a la maternidad como un elemento central en la vida de las mujeres. En la época moderna, el lazo entre maternidad y crianza establecido se reafirmó, al grado de ser concebidos como un solo elemento. Actualmente, en la era postmoderna, la maternidad es vista más como una elección que como una obligación. Como se puede apreciar, el concepto de maternidad ha ido adoptando múltiples matices dependiendo del momento histórico y del contexto social al que se hace referencia, lo cual también repercute en la construcción de los modelos.

Estas transformaciones no pasaron por alto para algunos investigadores, siendo aquellos provenientes de los círculos franceses y anglosajones los primeros en identificar y resaltar que la maternidad es un 
concepto construido socialmente, pues responde a las necesidades de un grupo situado en un momento y en un lugar específico de la historia. Dentro de este círculo, fue la filósofa feminista francesa Elisabeth Badinter de las primeras investigadoras en exponer esta situación en uno de sus libros publicado en los años ochenta. Esta década marcó el inicio del interés por estudiar el tema, siendo la de los noventa donde se registró un incremento en la proliferación de literatura respecto del mismo, sobre todo aquella producida en las disciplinas enmarcadas en el área de las ciencias sociales (Fregoso, 2005).

El identificar cómo los integrantes de un grupo específico construyen el concepto de maternidad, ha sido uno de los intereses de las investigaciones realizadas en el área social. Para ello se han estudiado grupos de mujeres de diferentes edades -desde adolescentes hasta mujeres en la etapa de adultez madura- (Barceló, 2016; Hernández, 2016; Kehily, 2012; Llanes, 2012; Nóblega, 2009; Oviedo y García, 2011; Sampedro, Gómez y Montero, 2002; Sifuentes, 2014) y en diferentes circunstancias de vida -en situación de precariedad, con trabajo, con hijos, sin hijos, en épocas de guerra, etc.- (Ávila, 2005; Santillán, 2010; Turner y Norwood, 2013; Vidaurrázaga, 2005; Wagner, 2008). En estas investigaciones, algunos de los elementos que han surgido de manera constante en la construcción del concepto de maternidad son: la existencia del mito "mujer es igual a 
madre", la naturaleza institiva adjudicada a la maternidad, la importancia de la misma para la sociedad y el papel de los hijos, los cuales tienen diferentes implicaciones en la construcción del concepto de maternidad.

Uno de los mitos que se encuentra arraigado en la mayoría de las sociedades, es que ser mujer es igual a ser madre (Pinto, 2007; Pizzianato y CalessoMoreira, 2007). De tal manera que, pareciera que la plenitud de la feminidad sólo puede ser alcanzada cuando la maternidad se hace presente, convirtiéndose así en el eje articulador de la vida de las mujeres. Por tal motivo, la historia personal, las elecciones y los proyectos de estas últimas, se cree que deberían ser planeados alrededor de este evento. Para reafirmar este mito, la sociedad ha utilizado como pretexto la constitución física de la mujer, pues es ella quien está equipada biológicamente para poder llevar vida en su vientre, así como para nutrirla durante la gestación y después de la misma. Además, bajo esta misma constitución física, se justifica la creencia de que la maternidad es algo instintivo en la mujer.

La sociedad, al contemplar la maternidad como algo natural e instintivo, considera que se encuentra inscrito en el destino de toda mujer (Arvelo, 2004; Blásquez, 2010; Oliviera, 2014; Provencio, 2011; Sanhueza, 2005; Valladares, 2005). Así pues, la sociedad educa a la mujer para hacer de este evento parte fundamental de su vida. La naturaleza y el instinto también han sido utilizados para justificar la división 
sexual del trabajo y el desplazamiento de las mujeres al ámbito privado, de tal manera que se cree que las mujeres deberían estar enfocadas a los quehaceres hogareños, dejando de lado la búsqueda de la superación personal y profesional (Aler, 2006; Sanhueza, 2005; Trujillo, 2017). El apego a dichos lineamientos no sólo implica que la mujer encuentre la plenitud de su ser, sino que también sea reconocida por los miembros de la sociedad.

El reconocimiento social es el tercer elemento a partir del cual es articulado el concepto de maternidad. La mujer que se convierte en madre comienza a ocupar un lugar diferente no sólo entre su familia, sino también entre los miembros de la sociedad (Bueno y Teixeira, 2015; Llanes, 2012). Pasa de ser una mujer más, a una madre que contribuye a través de su cuerpo, de sus hijos y desde su hogar al crecimiento de su entorno. Esto último, reafirma la creencia de que su desarrollo se da en el ámbito privado (Aler, 2006; Sifuentes, 2014). Este elemento se encuentra tan presente como parte del concepto de maternidad, que múltiples investigaciones realizadas con adolescentes han encontrado que uno de los motivos por los cuales se embarazan, es precisamente para ser consideradas en las decisiones de su comunidad.

El último elemento utilizado es la presencia de los hijos y las tareas relacionados con ellos, tales como la procreación, la entrega del amor incondicional y la crianza, las cuales se consideran responsabilidad de la 
mujer (Davis, 2011; De la Concha y Osborne, 2004; Mora, Otálora y Recagno, 2005; Sánchez, 2016). Diversas investigaciones realizadas hasta el momento han puesto de manifiesto como la sociedad le recrimina a las mujeres que no las cumplen, llegando incluso a segregarlas quitándoles el título de madre o bien, refiriéndose a ellas utilizando adjetivos descalificadores (Aguilar, 2009; Niner, Cuthber y Ahmad, 2014).

Si bien las distintas investigaciones identifican cuales son los elementos más relevantes para la construcción del concepto de maternidad, no otorgan un panorama claro sobre cuáles son los discursos predominantes en las mujeres, es decir, aquellos a través de los cuales ellas construyen su realidad. Por este motivo, la presente investigación busca identificar cuáles son los modelos de maternidad propios de las prácticas discursivas de un grupo de mujeres aguascalentenses, dando cabida a las siguientes preguntas de investigación ¿qué modelos de maternidad son inherentes a las prácticas discursivas sobre el tema en las mujeres socialmente consideradas en edad de ser madre? ¿Cómo son esos modelos en cuanto a características principales y aspectos normativos?

Para responder a estas preguntas, se decidió estudiar el discurso dado por las mujeres en torno a la maternidad. Pero ¿a que se refiere dicho término? La palabra discurso no ha sido definida de manera unívoca. Existen tantos conceptos como autores y teorías que lo han estudiado (Burr, 1995; Íñiguez y 
Antaki, 1998; Potter y Wetherell, 1987). Para objeto de esta investigación, cuando se habla de discurso, éste no sólo se referirá al lenguaje hablado o escrito, sino también a elementos tales como imágenes y fotografías, que dan un marco de referencia de cómo se comprende una determinada situación en un lugar y momento específico y que, como recurso social, promueve el mantenimiento de actividades y prácticas sociales específicas. Así pues, el discurso puede ser considerado como objeto de estudio, mismo que resulta de particular interés para diferentes teorías, entre las cuales se encuentra el Análisis del Discurso (en lo sucesivo $A D$ ).

El AD es una corriente teórica-metodológica que se circunscribe dentro del Construccionismo Social y cuyo principal objetivo es estudiar cómo las prácticas lingüísticas actúan manteniendo y promoviendo las relaciones sociales, sacando a la luz el poder del lenguaje como una práctica constitutiva y regulatoria (Íñiguez y Antaki, 1998) reconociendo así su importancia en la vida social. Para estudiarlo, el $A D$ debe enfocarse a la identificación de los textos, pues estos se encargarán de dar cuenta de los significados convenidos socialmente y reflejarán cómo son construidas las situaciones, los objetos y los sujetos en un determinado contexto sociocultural y momento histórico; así pues, la tarea metodológica del $A D$ consistirá centrarse en obtener los repertorios interpretativos 
contenidos en los textos. Potter y Wetherell los definen como

sistemas de términos usados recurrentemente para caracterizar y evaluar acciones, eventos y otros fenómenos. Un repertorio, como los repertorios empiricistas y contingentes, son usados a través de un rango limitado de términos en construcciones estilísticas y gramaticales particulares. Con frecuencia un repertorio se organizará alrededor de metáforas y otras figuras del habla. (1987, p. 149)

Para identificar dichos repertorios, es necesario realizar dos tareas mutuamente relacionadas. La primera consiste en identificar patrones de variabilidad y de consistencia, y la segunda consisten en la descripción de las funciones del texto y sus consecuencias. La variabilidad se refiere al hecho de que las mismas acciones, eventos o creencias son descritas mediante el discurso, en distintas circunstancias de modos distintos, ajustándose a los diferentes contextos en el que éste se despliega, dando cuenta de un mismo objeto de formas diversas; mientras que la consistencia está relacionada con la circunstancia en la que se presenta el discurso, de tal manera que éste se construye de modos distintos según la circunstancia (Sisto, 2012).

A partir de lo anterior, se debe hipotetizar la función que cada discurso tiene en el contexto en el cual es utilizado de forma recurrente. En palabras de 
Potter y Wetherell "el análisis debe mostrarnos cómo el discurso se articula y encaja junto, y como la estructura discursiva produce efectos y funciones" (1987, p. 170), lo cual se corresponde con la segunda tarea a realizar para identificar los repertorios interpretativos.

\section{Método}

Se realizó un estudio cualitativo de tipo discursivo con mujeres adultas residentes en la ciudad de Aguascalientes a través de grupos focales.

\section{Participantes}

La selección de las participantes obedeció a un criterio no probabilístico por conveniencia. Participaron un total de 29 mujeres adultas distribuidas en cuatro grupos. Las edades de las participantes oscilaron entre los 23 y los 37 años. En todos los casos, el nivel educativo fue igual o mayor a licenciatura. Algunas de las participantes tenían hijos mientras que otras no, criterio de variabilidad relevante en las conversaciones sobre maternidad.

\section{Instrumento}

Se trabajó con grupos focales a partir de una guía semi-estructurada. Los temas que se abordaron fueron: (a) la forma ideal de ser madre y sus características; (b) 
la existencia de parámetros psicológicos y/o sociales para convertirse en madre; (c) las tareas, responsabilidades y deberes que se le adjudican a las mujeres que se han convertido en madres; (d) el papel de los hijos en la maternidad; (e) qué o quienes dictan lo que debe ser y hacer una madre; y (f) la obligatoriedad de las mujeres para convertirse en madres. La libertad que otorga este tipo de entrevista permitió responder sobre todo a las necesidades del grupo, más que seguir una secuencia estricta de preguntas.

\section{Procedimiento}

En primer lugar, se determinó la composición de los grupos focales. Las condiciones clave estuvieron dadas por tres franjas de edad dentro del rango comprendido (23 a 27 años, 28 a 33 años y 34 a 37 años) y por el ser o no ser madre al momento de realizar el estudio. Después de establecidos los criterios, se procedió a contactar a las potenciales participantes utilizando dos medios de internet. El primero de ellos fue a través un cuestionario en línea elaborado en la plataforma "Formularios de Google", en el que se incluyó un apartado donde a cada una de las encuestadas se les solicitaba su información de contacto y su disposición para participar en los grupos presenciales que se harían más delante. Para la conformación de los grupos focales, sólo se contactó a aquellas mujeres que accedieron a participar y que cumplieron con los 
requisitos. El segundo medio fue la red social Facebook en donde se creó el grupo "¿Qué es eso a lo que llamamos maternidad?" y al cual se añadieron todos los contactos mujeres con los que la investigadora contaba y a todas las sugerencias de contacto de los miembros. Se utilizaron las publicaciones en el muro para convocar a las diversas reuniones - las cuales se realizaron a lo largo del segundo semestre del año 2017 -, especificando en cada una de ellas los requisitos necesarios - edad, nivel educativo y la existencia o no de hijos - para poder participar. La actividad de los grupos focales fue videograbada y posteriormente transcrita a la literalidad.

\section{Análisis}

El análisis consistió en seleccionar y examinar segmentos de texto e identificar los repertorios interpretativos presentes. Al mismo tiempo, estos repertorios se fueron interpretando para determinar cuáles eran las funciones que realizaban en el contexto específico en el que se presentaba, así como los contenidos a las que éstas se aplicaban. Posteriormente, se identificaron las variaciones en el discurso, así como las construcciones de maternidad que las mujeres hacían a través de éste. 
Resultados

Los resultados se organizan en torno a la caracterización y funciones discursivas de un modelo hegemónico de maternidad y algunas alternativas a ese modelo.

\section{Maternidad hegemónica}

En primer lugar, se presentan algunos elementos de este modelo hegemónico:

(1) Uno de los elementos de este modelo se refirió a la existencia de un instinto materno, es decir, un impulso biológico que se considera está presente en toda mujer y que implica el deseo de convertirse en madre.

(2) Un segundo componente fue el que se denominó identidad materna, el cual indica la posesión de un sentido de pertenencia para con la maternidad y que pareciera viene "integrado" per se en las mujeres, que las acompañará y las guiará en la búsqueda de la procreación y la crianza de los hijos, dotándoles de las habilidades físicas y psicológicas necesarias para hacerse cargo de ellos.

(3) Un tercer elemento fue el amor incondicional hacia los hijos, sentimiento que, al considerarse "inherente a la naturaleza de la mujer", se despliega en el momento mismo en que ésta se da cuenta que se está gestando vida en su vientre. 
(4) Otro componente fue la posesión de aptitudes y cualidades que le permiten a toda mujer cuidar de sus hijos, aunque a las mujeres se les dificultó especificar cuáles eran.

(5) Por último, se encontró que en el modelo hegemónico también se estableció la existencia de ciertas características socio-demográficas, educativas y psicológicas que la mujer debe cumplir para convertirse en madre, tales como ser una mujer heterosexual, tener hijos entre los 20 y 35 años de edad, estar casada -o tener una pareja estable_-, contar con un ingreso económico constante, haber cursado una carrera universitaria, comportarse de forma maternal, dedicarse exclusivamente a los hijos, así como renunciar y sacrificarse por ellos.

\section{Funciones}

Con respecto a las funciones discursivas relacionadas con el modelo hegemónico, los resultados se organizan en tres categorías, las cuales se muestran a continuación.

Consustancialidad. Es una función del discurso a través de la cual se habla de la existencia de ciertos comportamientos, cualidades y características de personalidad en la mujer, tales como instinto maternal, identidad materna, amor y cuidado hacia los hijos, los cuales se consideran inherentes a su naturaleza. Al 
respecto, una de las entrevistadas mencionó lo siguiente:

La madre tiende como a ciertas cualidades que le aportan a dar un servicio a... Pero más relacionada con el cuidado ¿no? O sea, no cuidado nada más como de enfermedad, si no como a cuidado, así de... Sí, o sea, así como muy amplio, como el cuidado de hasta formar alguien, o sea, como de formar como persona, como de mostrar o que tu punto de vista lo que es correcto, lo que es incorrecto, de qué es gracioso, de qué no es gracioso, que es ofensivo, de que no es ofensivo, como un cuidado de tú... después vas a estar. (Margarita, 29 años, una hija)

El discurso de esta participante comienza con la aseveración de que la "madre" posee "ciertas cualidades" que le permiten prestar un servicio. En la primera parte de esta oración, se delimita el campo de aplicabilidad de lo que se dice a las mujeres que son madres, como si esta conversión hiciera surgir automáticamente en ellas algo que permanecía latente en su ser y se activara en ese preciso momento. Otra de las características de la primera oración es la ausencia de especificidad, pues si bien se habla de cualidades, no se menciona cuales son éstas. Tan sólo se sabe que la mujer posee diversas cualidades, pero a las que hay que prestarles atención, las que son destacadas por el discurso, son aquellas que se relacionan con el brindarle un servicio al otro, en 
específico, las que hacen referencia al cuidado. El tipo de cuidado del que se habla también resulta un tanto inespecífico, pareciera ser todo y nada a la vez; todo porque su impacto es continuo, perdurable incluso después de la ausencia física de la madre, y nada porque resulta complicado darle una forma, darle un nombre.

Justificación. Se trata de una función que era utilizada por las mujeres para acreditar el comportamiento de una persona que seguían la norma social establecida. Una de las mujeres entrevistadas mencionó la importancia de la edad para convertirse en madre, expresando lo siguiente:

Bueno, yo sí creo que también es un... O sea, médicamente hablando, es un factor la edad. O sea, yo recuerdo cuando trabajé muchos años con niños con discapacidad, pues, igual, ¿no? O sea, llegaban las mamás de 18 con sus niños con parálisis y yo decía: "¿Yo que he hecho toda mi vida?, Éstas ya tienen cuatro y yo sigo aquí sin hijos". Pero sí, creo que médicamente ser una mamá muy joven y ser una mamá mayor, o sea, después de los 35 años, pues son factores de riesgo. O sea, genéticamente no lo podemos evitar, no lo podemos negar. O sea, definitivamente yo que trabajé mucho tiempo con niños con discapacidad sí digo... Voy a cumplir 34 años, no me siento grande pero sí digo: "ay, a ver, física, mentalmente y psicológicamente no me siento lista para tener otro hijo, a esta edad, sé que no soy grande 
peor yo ya no quiero". Y sí, también por edad, por todo digo: "pues, es que entre más grande la cosa se complica más". (Marimar, 33 años, una hija)

En esta investigación se encontró que existe de un periodo de edad en el que la sociedad considera idóneo que las mujeres se convirtieran en madres, y el cual se encuentra entre los 20 y 35 años. $Y$ es al abordar este tema, que Marimar retoma su experiencia laboral y sus conocimientos sobre lo dicho por el discurso médico para justificar el porqué las mujeres deberían apegarse a este lineamiento pues, en caso de no hacerlo, existe una repercusión para los/as hijos/as, que en este caso específico se refería a la parálisis cerebral. Ella continúa justificando su proceder al indicar que, si bien aún se encuentra dentro del periodo medicamente establecido, ella ya no desea convertirse en madre al no sentirse "mentalmente" preparada. Así pues, el peso de los discursos sociales y médicos han adquirido fuerza sobre el propio, pues ella busca cumplir con su ellos para evitar la posibilidad de que su hijo/a sufra las consecuencias en caso de no hacerlo.

Locus de control externo. A través de esta función, las mujeres depositaban en un tercero la responsabilidad de lo dicho y/o de sus acciones. Tal es el caso de Eva, quien mencionó que, para ella, su abuela se convirtió en su punto de referencia en cuanto a este tema: 
Mi abuela me dijo una vez, yo creo que fue mucho de lo que me movió todo este plan de vida que yo traía. Yo desde chica mi plan de vida era trabajar y ver por mis padres. Esa era mi... Desde chiquita. $Y$ mi hermana era ser mamá y mi otra hermana también. $Y$ yo era así como que el cuidar. Yo nunca tuve presente ni casarme ni ser mamá y bla bla bla. Y quien me vino a mover todo en cuanto a planes fue mi abuela, cuando entra en coma a mí me toca entrar, me fui a despedir de ella, porque ya eran 2 meses en coma, y despierta en ese momento, porque pus me estaba despidiendo de ella, y despertó. Y me dijo "La vida que tú quieres, no es vida. Al menos consigue alguien con quien puedas platicar cuando estés vieja". Entonces me quedé, o sea, neta, eso me influyó mucho y yo me quedé así, no pues, sí es cierto. Porque ella, para ella no fue vida el haberse peleado con su esposo. Mi abuelo ahí en la casa, pero no, nunca se hablaron después de lo que hizo. Entonces fue mucho el factor que me movió, me influenció a mover mis planes de "Bueno, me voy a casar y si no consigo pareja, voy a buscar embarazarme, pero yo sola". Y eso fue. Pero realmente mi plan de vida al final era cuidar a mis papás y estar yo sola con ellos. Yo por ellos, pues. (34 años, sin hijos/as)

En intervenciones anteriores, Eva había mencionado que en su plan de vida inicial no había contemplado el casarse y tener hijos/as. No obstante, después de que su abuela cayó enferma y antes de morir le dirigió unas palabras, decidió cambiar de opinión, sobre todo en lo que a maternidad se refería. 
Si bien, Eva fue quien a final de cuentas decidió hacerlo, a lo largo de su intervención responsabilizó a su abuela y a lo vivido por ésta, de los cambios en sus planes de vida. Así pues, no se trataba de ella, sino de alguien más quien la convenció de renunciar a sus planes iniciales y convertirse en madre.

\section{Modelos alternativos}

Las mujeres también indicaron la existencia de otros modelos diferentes al establecido socialmente de ejercer la maternidad. Uno de estos modelos fue el de maternidad moderna, el cual se caracterizó por la falta de rigidez y la apertura a nuevas posibilidades para ejercer la maternidad. Si bien el convertirse en madre se sigue contemplando como una meta de vida, el hacerlo bajo los propios lineamientos es lo que principalmente caracteriza a este modelo.

El segundo modelo identificado fue el de maternidad como elección. En éste, el convertirse en madre fue considerado una posibilidad y no una obligación, de tal manera que el instinto materno, la identidad materna y el amor hacia los hijos, fueron puestos en tela de juicio como elementos inherentes a la naturaleza de la mujer. Además, el ámbito público fue visto como el terreno ideal para desarrollarse y obtener reconocimiento social. Así pues, la maternidad fue dejada de lado por las mujeres para dar paso a las metas y a los deseos que no se relacionaran con ésta. 
Funciones alternativas

En cuanto a las funciones discursivas relacionadas con los modelos alternativos, se encontraron un total de seis, las cuales fueron utilizadas por las mujeres para cuestionar, e incluso oponerse, al modelo hegemónico socialmente establecido. En los siguientes párrafos, se ejemplificará cada una.

Disclaimer. Propuesta por Potter (1988) y quien la definió como un mecanismo verbal utilizado para alejar atribuciones potencialmente desagradables, así como para mantener coherencia en el discurso en caso de que éste se modifique. En el caso del tema de la maternidad, las mujeres la utilizaron para alejar de sí mismas las prescripciones establecidas socialmente, depositándolas en un tercero, quien adoptó la forma de otra mujer u otro grupo social. De igual manera, éste fue utilizado para colocar su experiencia como referencia cuando hablaban de maternidad, oponiéndose sutilmente a las normas establecidas.

Para hablar sobre la maternidad y cuestiones relacionadas con ésta, algunas de las entrevistadas se remitieron a las experiencias de otras mujeres que la han vivido directamente y con las cuales han tenido contacto. Tal es el caso de la siguiente participante quien, al no tener hijos/as, habla sobre lo que le han dicho al respecto: 
ENTREVISTADORA: Oigan, y hablando de los hijos, ¿cómo para qué tendremos hijos? ¿Para qué serán los pequeñitos?

DORA: Pues a mí lo que me han, me han dicho es como para que no te quedes sola y luego tengas como alguien que vea por ti. Es como por lo regular lo que he escuchado. Tengo, este, familiares que son mamás solteras y dijeron, así como de "mi última opción es que si no encuentro pareja, voy a ser mamá soltera y voy a tener un hijo porque no me quiero quedar sola". Entonces, "como quiero asegurar que cuando yo esté mayor haya alguien que me cuide". Es como el discurso que yo he escuchado. Pero pues la verdad no lo, bueno, yo no creo en eso, pero es lo que más en mi familia es cómo lo que se dice. "¿Y luego quién te va a cuidar? ¿Y luego cuando estés viejito como le vas a hacer?" Así como es todo es, es ese discurso de "si no tienes hijos, ahorita, cuando ya estés grande te vas a arrepentir porque no vas a tener quien te cuide, no vas a tener felicidad", así como de, son ese tipo de cosas como que se, como que se mencionan. Bueno... (23 años, sin hijos/as)

En una parte del desarrollo del grupo focal, la entrevistadora hace una pregunta que trata sobre el objetivo que tienen los hijos/as en la vida de una mujer. Dora, al no ser madre, responde desde lo que las otras mujeres le han dicho al respecto, incluyendo aquellas que forman parte de su familia. De acuerdo a éstas, los hijos/as cumplen funciones de cuidado y compañía 
para con la madre. Esta declaración es potencialmente desagradable pues, entre otras cosas, implica la privación de la libre decisión; Dora se aleja de las consecuencias de lo dicho aclarando que esto es propio de su familia, no de ella.

Locus de control interno. Algunas de las entrevistadas comentaron que la maternidad es una cuestión de decisión; si bien la sociedad establece una serie de lineamientos que deben ser cubiertos por las mujeres, son ellas mismas quienes tienen la última palabra respecto de cuando y cómo, e incluso, si deciden no tener hijos/as. Tal es el caso de la siguiente participante, quien comentó cómo sus familiares la presionaban y cual fue su reacción ante tal situación:

No, pos, yo igual nada más así comentarios hirientes. [Todas ríen] Mi papá “iAy! ¡Qué ganas de tener un nieto! ¡Ay! Me voy a morir y no voy a conocer a mis nietos" y cositas así, pero, no son así como muy muy insistentes pero sí se siente como esos comentarios este que hacen de vez en cuando, te ponen a pensar justo eso ¿no?, también. La edad, que si lo biológico. Pero a veces yo pienso que eso que importa. O sea, yo pienso que tener un hijo es para darle una familia, para estar con él, para, o sea, es algo que va a cambiar tu vida. No nada más por decir jay, se me acaba el tiempo y necesito tener un hijo". Entonces, ¿es nada más por eso? ¿para cumplir con lo que se te está exigiendo, que ya debes de tener un hijo? Y yo digo, bueno, si llega un momento en el que se me 
acaba el tiempo biológicamente para tener un hijo y yo no encontré a una pareja con quien quiera estar, yo no encontré a alguien con el que dijera "Uh, guau, iquiero tener un hijo!" La verdad ahorita no lo siento, yo digo, ¡uy, quiero tener un hijo! No, la verdad no. Siento que debo de estar como en una situación más estable y alguien que me acompañe en esa aventura de ser madre. Si no, digo, ¿pues para qué? O sea, ¿qué caso tiene? Entonces este independientemente de la cuestión biológica y todo eso, yo pienso en otras cosas que creo son más importantes para tomar una decisión de tener un hijo. Incluso si te casas o algo, si no te sientes este preparada para para ser mamá pues no lo hagas. Es que, ¡me ha tocado ver a tantos niños sufrir! Trabajé un tiempo con, con niños y las familias son un desastre, un caos y digo ipobres niños! Está bien difícil ser papá ahorita. Entonces yo nada más por eso trato de ignorar toda la presión que me rodea. Digo ¡Digan lo que quieran! Al final es mi vida, es mi cuerpo, yo decidiré si en algún momento quiero tener un hijo. (Celia, 26 años, sin hijos/as)

Al inicio de su intervención, ella señala como sus familiares, específicamente su padre, le hace comentarios en los que le reprocha de forma indirecta el que todavía no tenga hijos/as, señalándole para ello que aún no lo ha convertido en abuelo. Si bien Celia dice que estos no son insistentes, sí la hacen pensar en su situación actual, pues de acuerdo a la norma social ella se encuentra en el periodo indicado para convertirse en madre. No obstante, vuelve a retomar el control sobre 
lo que dice al indicar que la exigencia social no es elemento suficiente para decidir convertirse en madre en ese momento, sino que para ella el tener un hijo implica un compromiso para con éste. Añade, además, que aún no existe en su persona el deseo de convertirse en madre, ni una pareja con la que quiera estar y compartir esta etapa de su vida. Inclusive, menciona que el tener esta última, tampoco es garantía de que el deseo se presente inmediatamente. Así pues, a lo largo de su intervención Celia se va empoderando de su cuerpo y sus decisiones, lo cual utiliza para no ceder ante las presiones externas de las que es objeto.

Comparación. Función utilizada por las mujeres para exponer las diferencias existentes entre los discursos, principalmente entre aquellos desplegados en épocas diferentes y entre aquellos dirigidos a los hombres, concluyendo así que éstos no son estáticos, sino que éstos se modifican a través del tiempo. La siguiente participante comparó dos épocas de su vida:

Antes, yo siempre fui muy de nenucos y de bebés, $y$ era un amor impresionante a mis muñecos. $Y$ yo sentía que el ser mamá era de: "súper bonito, los bebés tan lindos, sus caritas, sonriendo y todo". Cuando llega mi hijo yo no estaba preparada para ser mamá, entonces llega de sopetón un niño chillón, un niño que no te deja dormir, que no te deja ni ir al baño. Entonces digo: ¿dónde está la belleza de cuando pensaba en ser mamá? Entonces fue así de: "No, no, 
esto no es lo que esperaba". Menos cuando... a lo mejor cuando tú planeas un hijo, quizá, te pones a investigar y dices: "Wow, ya viene esto y ya viene esto", pero para mí fue de: "Vas a ser mamá y ahí está el chiquillo" [Ríe brevemente]. No, no era el momento. Entonces pues sí, bueno, para mí sí fue un shock. (América, 31 años, 2 hijos/as).

América mencionó que, durante su niñez, la idea que tenía con respecto a la maternidad, así como los sentimientos que ésta le generaba, eran muy diferentes a los que experimenta en la actualidad. De tal manera que esta idea le resultaba muy atractiva durante su infancia, pero no así en su adultez, cuando realmente se convirtió en madre. Además, el confrontar la fantasía con la realidad, entre esto el hecho de que los bebés humanos no son parecidos a los muñecos con los que ella jugaba, provocaron un cambio en su discurso.

Conflicto. Fue una forma de acción discursiva utilizada para manifestar la coexistencia de tendencias contradictorias en el propio discurso, las cuales a las mujeres les generaban incertidumbre con respecto a decisiones futuras relacionadas con la maternidad. Éste se presentó principalmente de dos maneras, siendo una de ellas cuando las mujeres cotejaban las exigencias de su entorno social con sus propios deseos y metas, y los cuales eran opuestos; y la segunda forma fue manifestando abiertamente su oposición ante la 
normativa social impuesta, utilizando ejemplos propios y/o ajenos para ello.

Otra de las participantes habló sobre la existencia de un conflicto entre la forma en que otras mujeres de su familia vivieron su maternidad y lo que ella ha construido con respecto al tema hasta este momento:

Yo tengo por ahí un choque entre, bueno, ese cómo debería ser la maternidad respecto a como han sido las mamás de tu familia, por ejemplo, la maternidad que llevó a cabo mi abuela, o la maternidad que llevó a cabo mi mamá. Entonces el choque sería en, ahora cómo yo veo, lo que debiera ser. Hay algunas cosas que acepto porque me gusta, como el cuidado, o sea, a lo mejor alguien tiene que estar como al pendiente, en este caso, bueno, yo sé que pueden estar papá y mamá, pero si detecto que... Bueno, también por la figura paterna que hay en mi casa, ¿no?, que sería un tanto diferente la forma de llevar a cabo estas actividades de cuidado de papá y de mamá, ¿sí? Entonces yo creo que el choque que yo tendría es por las formas, de lo que estudias, lo que ves en la vida cotidiana te hace, pues, no sé, como plantear preguntas a ¿porqué siempre debería ser tal cual situación o tal cual rol? Entonces ahí sería como mi choque. (Fernanda, 26 años, sin hijos/as)

Ella comienza su intervención hablando sobre este conflicto, al cual denomina "choque". Resulta interesante la elección de este término, pues éste no sólo indica el encuentro entre dos elementos, sino que 
también habla sobre la intensidad con la que se da este encuentro, que para este caso parece ser mayor. Así pues, existe un conflicto intenso entre dos elementos los cuales son, por un lado, la maternidad tal como la llevaron su abuela y su madre, y, por el otro, la forma en que Fernanda la ha construido a partir de sus experiencias y sus conocimientos. Este último elemento se ha nutrido por otros discursos que cuestionan la legitimidad de la norma, del deber ser, y que llevan a la participante a construir nuevas formas de ser madre, independientemente de que durante su intervención no quede claro cuáles son. Y la confrontación se da justamente entre la tradición y su ruptura, entre lo que aprendió de sus ancestros y el conocimiento que se nutre de lo nuevo.

Disyuntiva. Función utilizada por las mujeres para justificar sus decisiones, al considerar que existen actividades que son incompatibles con la maternidad. Esta justificación podía darse en dos sentidos: el primero, en el que se buscaba rescatar el propio deseo de superación personal y/o profesional y así retomar el control sobre la propia vida, y el segundo, donde la maternidad podía ser utilizada como excusa para no alcanzar el desarrollo personal y/o profesional. Así pues, la primera forma es la que abrió mayores posibilidades de transformación del discurso sobre la maternidad, al generar alternativas diferentes a las 
establecidas en el modelo hegemónico. Al respecto, una de las participantes comentó:

Es que yo, por ejemplo, yo más haya que de echar desmadre, yo así siento que sigo explorando en mí misma. Y, por ejemplo, el rollo del teatro, pus no sé, cada vez va siendo más parte de mi vida, y a veces quiero escribir más de teatro, y escribir, así como que cosas y digo si tuviera bebés, tal vez no me arriesgaría tanto como a lanzarme, a como... iAy! Pus voy a hacer teatro, por todo un año, me voy a dedicar a hacer teatro, a escribir, a actuar, lo que sea, pero... Tal vez ahorita siento que lo podría hacer, explorar en esa parte de mí. Pero si tuviera hijos pues no lo haría. (Lupita, 27 años, sin hijos/as)

Esta entrevistada explicaba los motivos por los cuales aún no se había convertido en madre, mismos que estaban relacionados con su deseo de involucrarse y desarrollarse más en el teatro. Sin embargo, cuando considera la posibilidad de tener bebés, frena su deseo, al grado de considerar que éste y la maternidad son incompatibles.

Reflexividad. Fue utilizada por las participantes para hablar sobre los sentimientos que les generaban los temas relacionados con la maternidad, y entre los que se encontraron la culpa y la desesperación. El primero se presentó cuando las mujeres no experimentaban las emociones que la sociedad les dijo se harían presentes cuando se convirtieran en madres, tales como amor 
incondicional y desmedido hacia sus bebés, paciencia, etc.; mientras que la segunda, se presentó como una forma de rechazo al modelo hegemónico establecido. Con respecto del primero, una de las entrevistadas dijo:

Yo también me quedé pensando, antes y después. También antes era todo maravilloso y qué bonito y todo mundo te dice: "No, cuando lo veas te vas a derretir de amor y amor a primera vista". Entonces, también me cree expectativas. Para empezar, yo me acababa de casar, tenía dos meses de casada cuando me enteré que estaba embarazada, no estaba en nuestros planes. Sin embargo, pues, adelante, viene un bebé qué bonito, que padre. Yo los primeros meses, por ejemplo, no sentía esa emoción porque no lo había planeado, porque no lo esperaba así. Teníamos un viaje en puerta que se canceló, etc. y me sentía culpable. Yo creo que también esas expectativas que nos crean acerca de la maternidad, si no se cumplen o tú sientes que no las cumples, o en mi caso, yo voy a hablar por mí, yo sentía esa culpabilidad. "Dios es que ¿por qué no estoy feliz si se supondría que debería estar feliz?" Más avanzado el embarazo ya cambió eso un poco, lo disfruté mucho. Cuando llega mi bebé, la veo salir de mí y no me derretí de amor, o sea, no, fue de: ¿tú quien eres, extraña? No. Obviamente va pasando el tiempo y ahorita me derrito de amor y es un amor que jamás había conocido, pero igual vuelvo a sentir culpa, sí, porque dije: "sí la quiero, es mi hija", pero no era ese amor que salía de mí y que me superaba. Entonces, también ahí sentí como culpa, obviamente es algo que 
no platicas como tan fácil porque, pues, no sé... Me van a señalar o me van a decir "¿cómo que no la quieres?" O sea, fue un proceso. (Denisse, 30 años, una hija)

Lo primero que hace Denisse es comparar el antes y el después; el antes, donde el ser madre era lo más bello y donde el amor materno fluía justo en el momento en el que se veía al bebé; este discurso fue interiorizado e idealizado por ella. $\mathrm{Y}$ el después la enfrentó directamente con la maternidad, una maternidad no planificada y a la que responsabilizó de haber tomado la decisión de cancelar varios planes. La idealización de este evento hizo eco en ella, de tal manera que se sintió culpable por no experimentar las emociones que le dijeron que sentiría. Esta culpabilidad también se vio reflejada en su argumento posterior, donde explicó que estas emociones sí se hicieron presentes conforme pasó el tiempo, como si quisiera quitarle fuerza a lo anteriormente dicho al destacar que si llegó a amar a su hija.

\section{Discusión}

La maternidad se construye a través de las palabras, de tal manera que aquello que socialmente se considera algo natural, generalmente se refiere a una serie de categorías convenidas y transmitidas a través del discurso. No es que la mujer nazca para convertirse en madre, sino que a través del tiempo se ha 
convenido que la misión de ésta, al poseer órganos altamente especializados, consistirá en darles uso y contribuir con el desarrollo del grupo social al que pertenece. Asimismo, no es que la mujer posea un instinto maternal, sino que a través del tiempo se le ha hecho creer que una de las formas, sino es que la única, para ser reconocida en la sociedad es a través de la gestación y la crianza de los/as hijos/as, por lo que tiene que desarrollar las habilidades necesarias para lograrlo.

En cuanto a los modelos de maternidad que se buscaron identificar a través de esta investigación, se encontró que a pesar de las transformaciones estructurales y económicas que ha experimentado la sociedad, aún prevalece la existencia de un modelo que les es impuesto a las mujeres y que posee como característica principal el restringir su comportamiento, bajo el argumento del "ser". Este modelo ha sido utilizado para despojarlas de todo poder sobre sus cuerpos, sus deseos y sus decisiones, quedando a la merced de lo que la sociedad establece como adecuado.

No obstante, la maternidad no es un evento obligado para las mujeres, la maternidad no es algo que las termine por definir como tales. La maternidad puede o no hacerse presente en sus vidas, y ellas tienen todo el derecho de aceptarla o rechazarla. En el grupo de mujeres entrevistadas, se vio que esto está sucediendo, de tal manera que ellas han practicado 
nuevas estrategias discursivas que les permiten generar nuevas alternativas en cuanto a las formas de ser mujer. $Y$ es a través de la generación de estas nuevas alternativas, que las mujeres han podido construir otros modelos de maternidad diferentes al impuesto socialmente.

\section{Referencias}

Aguilar, P. L. (2009). De silencios y abandonos: La construcción discursiva de la maternidad adolescente en contextos de pobreza.

Sexualidad, Salud y Sociedad, 3, 130-153.

Recuperado de

https://www.e-publicacoes.uerj.br/index.php/Sexua lidadSaludySociedad/article/view/28/477

Aler, I. (2006). La transformación de la maternidad en la sociedad española 1975-2005. Otra visión sociológica. Sevilla: Fundación Centro de Estudios Andaluces.

Arvelo, L. (2004). Maternidad, paternidad y género. Otras miradas, 4(22), 92-98.

Ávila, Y. (2005). Mujeres frente a los espejos de la maternidad: las que eligen no ser madres.

Desacatos, 17, 107-126. doi:10.29340/17.1060

Barceló, M. I. (2016). Un camino hacia la maternidad pospatriarcal. Revista de Antropología Iberoamericana, 11(1), 131-152. doi:10.11156/aibr.110107

Barrantes, K. y Cubero, M.F. (2014). La maternidad como un constructo social determinante en el rol 
de la feminidad. Revista Wimb Lu, 9(1), 29-42.

doi:10.15517/wl.v9i1.15248

Blázquez, M. (2010). Emociones ante la maternidad: de los modelos impuestos a las constelaciones de las mujeres. Ankulegi, 14, 81-92. Recuperado de https://aldizkaria.ankulegi.org/index.php/ankulegi/a rticle/view/28

Bueno, N. y Teixeira, E. N. (2015). Social construction of meanings about pregnancy-motherhood among adolescents. Texto Contexto, Enferm, Florianápolis, 24(4), 1139-1147. doi:10.1590/0104-0707201500000450015

Burr, V. (1995). An introduction to social constructions. New York: Routledge.

Davis, R. A. (2011). Mother-child relations and the discourse of maternity. Ethics and Education, 6(2), 125-139. doi:10.1080/17449642.2011.622979

De la Concha, A. y Osborne, R. (2004). Las mujeres y los niños primero. Los discursos de la maternidad. Barcelona: Icaria.

Fregoso, A. (2005). En plural: la(s) maternidad(es). Una mirada desde España al escenario internacional. Revista de Estudios de Género La Ventana, 22, 286-291. doi:10.32870/lv.v3i22.790

Hernández, E. (2016). La maternidad después de... Estudio etnográfico de la maternidad primípara "tardía" en España. AIBR. Revista de Antropología Iberoamericana, 11(1), 79-103. doi:10.11156/aibr.110105

Íñiguez, L. y Antaki, C. (1998). Análisis del discurso. Revista Anthropos, 177, 59-66. 
Kehily, M. J. (2012). Young motherhood in a changing maternal world. Educação, Sociedade \& Culturas, 37, 7-21. Recuperado de https://www.fpce.up.pt/ciie/sites/default/files/ESC3 $7 \mathrm{M}$ Kehily.pdf

Llanes, N. (2012). Acercamientos teóricos a la maternidad adolescente como experiencia subjetiva. Sociológica, 27(77), 235-266.

Recuperado de http://www.sociologicamexico.azc.uam.mx/index.p $\mathrm{hp} /$ Sociologica/article/view/66/58

Molina, M.E. (2006). Transformaciones histórico culturales del concepto de maternidad y sus repercusiones en la identidad de la mujer. Psykhe, 15(2), 93-103. doi:10.4067/S071822282006000200009

Mora, L.; Otálora, C. y Recagno, I. (2005). El hombre y la mujer frente al hijo: Diferentes voces sobre sus significados. Psykhe, 14(2), 119-132. doi:10.4067I S0718-22282005000200010

Niner, S.; Cuthber, D. y Ahmad, Y. (2014). Good mothers, bad mothers: Motherhood, modernity and politics in representations of child abuse in Malasyia's English-language newspaper. Feminist Media Studies, 14(6), 993-1011. doi:10.1080/14680777.2013.854822

Nóblega, M. (2009). La maternidad en la vida de las adolescentes: implicancias para la acción. Revista de Psicología, 27(1), 30-54. doi:10.18800/psico.200901.002

Oiberman, A. (2004). Historia de las madres en occidente; repensar la maternidad. Psicodebate. 
Psicología, Cultura y Sociedad, 5, 115-130. doi:10.18682/pd.v5i0.456

Oliviera, T. (2014). La maternidad como resistencia. El discurso del cuerpo. En C. F. Miranda; F. Pattaro y M. N. González. Género y Discurso. (pp. 87-139). Bogotá: Ediciones Universidad Simón Bolívar.

Oviedo, M. y García, M. (2011). El embarazo en situación de adolescencia: una impostura en la subjetividad femenina. Revista Latinoamericana de Ciencias Sociales, Niñez y Juventud, 2(9), 929-943. Recuperado de http://www.scielo.org.co/ pdf/rlcs/v9n2/v9n2a29.pdf

Pinto, V. (2007). Madres e hijos en los 90: Las representaciones sociales de la maternidad en la revista Para Ti. Opción, 23(53), 22-37.

Recuperado de http://ve.scielo.org/scielo.php? script=sci_arttext\&pid=S101215872007000200003

Pizzianato, A. y Calesso-Moreira, M. (2007). Identidad, maternidad y feminilidad: Retos de la contemporaneidad. Psico, 38(3), 224-232.

Recuperado de https://revistaseletronicas.pucrs.br/ojs/index .php/revistapsico/article/view/2883

Potter, J. y Wetherell, M. (1987). Discourse and Social Psychology. Londres: Sage.

Provencio, G. (2011). La trampa discursiva y el elogio a la maternidad cubana del siglo XIX. Americanía, 1, 42-73. Recuperado de https://www.upo.es/revistas/index.php/americania/ article/view/315/304 
Real Academia Española. (2014). Modelo. En Diccionario de la Lengua Española (23a ed.).

Recuperado de http://dle.rae.es/?id=PTk5Wk1

Sampedro, R.; Gómez, M. V. y Montero, M. (2002).

Maternidad tardía: incidencias, perfiles y

discursos. Revista de Metodología de Ciencias

Sociales, 5, 11-36.

doi:10.5944/empiria.5.2002.911

Sánchez, M. (2016). Construcción social de la maternidad: el papel de las mujeres en sociedad.

Opción, 32(13), 921-953. Recuperado de https://dialnet.unirioja.es/servlet/articulo? codigo $=5844698$

Sanhueza, T. (2005). De prácticas y significancias de la maternidad, transformaciones en identidad de género en América Latina. Revista de Estudios de Género La Ventana, 22, 146-188. Recuperado de http://www.scielo.org.mx/pdf/laven/v3n22/14059436-laven-3-22-146.pdf

Santillán, M. (2010). El discurso tradicionalista sobre la maternidad: Excélsior y las madres políticas durante el avilacamachismo. Secuencia, 77, 90110. Recuperado de http://ref.scielo.org/msn4h9 Sifuentes, L. (2014). Being a woman poor and young. Telenovelas and the cultural mediations of the gender identity. Feminist Media Studies, 14(6), 976-992. doi:10.1080/14680777.2014.947721

Trujillo, M. (2017). Maternidad y prostitución ¿contradictorias y excluyentes?. Revista Estudios Feministas, 25(1), 163-181. doi:10.1590/18069584.2017v25n1p163 
Turner, P. K. y Norwood, K. (2013). Unbounded motherhood: embodying a good working mother identity. Management Communication Quarterly, 27(3), 396-424. doi:10.1177/0893318913491461

Valladares, B. (2005). La maternidad y los medios masivos de comunicación. Un análisis de artículos periodísticos y propaganda comercial en Costa Rica. Diálogos, Revista Electrónica de Historia, 5(1-2), 1-19. doi:10.15517/dre.v5i1-2.6235

Vidaurrázaga, T. (2005). Maternidades en resistencia: reconstruyendo la memoria desde la desvictimización. Revista de Estudios de Género, La Ventana, 22, 110-145.

Wagner, H. (2008). Maternidad trasnacional: discursos, estereotipos y prácticas. En G. Herrera y J. Ramírez. América Latina Migrante: Estado, familias, identidades. (pp. 325-340). Ecuador: FLACSO, Sede Ecuador y Ministerio de Cultura de Ecuador. 


\section{(a) $(0 \Theta(1)$}

Esta obra está bajo una

\section{Licencia Creative Commons Atribución-NoComercial- Compartirlgual 4.0 Internacional}

Usted es libre de compartir o adaptar el material en cualquier medio o formato bajo las condiciones siguientes: (a) debe reconocer adecuadamente la autoría, proporcionar un enlace a la licencia e indicar si se han realizado cambios; (b) no puede utilizar el material para una finalidad comercial y (c) si remezcla, transforma o crea a partir del material, deberá difundir sus contribuciones bajo la misma licencia que el original.

Resumen de la licencia

https://creativecommons.org/licenses/by-nc-sa/4.0/deed.es_ES

Texto completo de la licencia https://creativecommons.org/licenses/by-nc-sa/4.0/legalcode 